\title{
OPEN Vertical distribution of soil available phosphorus and soil available potassium in the critical zone on the Loess Plateau, China
}

\author{
Hanyang Tian ${ }^{1,4}$, Jiangbo Qiao ${ }^{2}$, Yuanjun Zhu ${ }^{1,2 凶}$, Xiaoxu Jia ${ }^{3}$ \& Ming'an Shao ${ }^{2,3}$
}

Soil available phosphorus (SAP) and soil available potassium (SAK) are important elements in the growth of plants. However, limited data are available regarding the vertical distribution of SAP and SAK in deep soil profiles. In this study, we investigated the vertical variations in SAP and SAK in the critical zone on the Loess Plateau $(50-200 \mathrm{~m})$, China, by using classical statistical and geostatistical methods. The soil samples were collected from the top of the soil profile down to the bedrock by soil core drilling at five typical sites. SAP decreased throughout the profile. Whereas the SAK exhibited an increasing trend at all sites. The mean SAP concentration ranged from 0.94 to $32.56 \mathrm{mg} \mathrm{kg}^{-1}$ at the sampling sites and the SAK concentration ranged from 44.51 to $229.31 \mathrm{mg} \mathrm{kg}^{-1}$. At all of the sampling sites, SAK was significantly positively correlated with the depth and clay content, but there was a significantly negative correlation between the SAK and the sand content. The exponential model could fit most variograms of SAP and SAK at all sampling sites. The results obtained in this study to improve our comprehension of the SAP or SAK distribution conditions on the Loess Plateau, which is important for reasonable fertilizer application and vegetation planting practices.

Phosphorus $(\mathrm{P})$ and potassium $(\mathrm{K})$ are the main nutrient elements in plants. Among them, soil available P (SAP) and soil available K (SAK) can be directly used by plants. Therefore, SAP and SAK are effective indicators to judge soil fertility and plant growth. Determining the spatial distribution of SAP and SAK as well as the factors that influence them are important for implementing reasonable vegetation planting and fertilizer application practices.

The spatial distribution of SAP and SAK and their related factors had been studied widely at different scales. For example, Li et al. ${ }^{1}$ evaluated the spatial variations in the SAP and SAK in the Huanghuadianzi watershed. In addition, Bogunovic et al. $^{2}$ investigated the spatial distribution of soil chemical properties on an organic farm in Croatia. Chen et al. ${ }^{3}$ determined the characteristic distribution of the SAP and SAK in farmland in Lanzhou, China. However, most previous studies focused on the spatial distribution of the SAP and SAK in the upper soil layer $(<1 \mathrm{~m})$, few have considered their spatial distribution in deep soil layers.

The Loess Plateau has deep loess deposits that range in thickness from 30 to $200 \mathrm{~m}^{4}$ in China. Due to the low content of the soil nutrient and the groundwater depth of 50-100 $\mathrm{m}^{5}$, the formation and loss of deep soil nutrients caused by the participation of deep soil moisture in the water cycle have a certain impact on the biogeochemical cycle. For a long time, few studies had shown that the nutrient content of deep soil changes, most of which were concentrated in the surface layer of soil, it is very meaningful to study the changes in SAP and SAK contents in deep profiles.

The objectives of this study were: (1) to investigate the vertical distributions of the SAP and SAK in the critical zone on the Loess Plateau; (2) to evaluate the factors that influence the SAP and SAK distributions; and (3) to evaluate the spatial variations in SAP and SAK.

\footnotetext{
${ }^{1}$ State Key Laboratory of Soil Erosion and Dryland Farming on the Loess Plateau, Institute of Soil and Water Conservation, Chinese Academy of Sciences and Ministry of Water Resources, Yangling 712100, China. ${ }^{2}$ State Key Laboratory of Soil Erosion and Dryland Agriculture on the Loess Plateau, Northwest A\&F University, Yangling 712100, China. ${ }^{3}$ Key Laboratory of Ecosystem Network Observation and Modeling, Institute of Geographic Sciences and Natural Resources Research, Chinese Academy of Sciences, Beijing 100101, China. ${ }^{4}$ University of Chinese Academy of Sciences, Beijing 100101, China. ${ }^{\circledR}$ email: zhuyuanjun@foxmail.com
} 

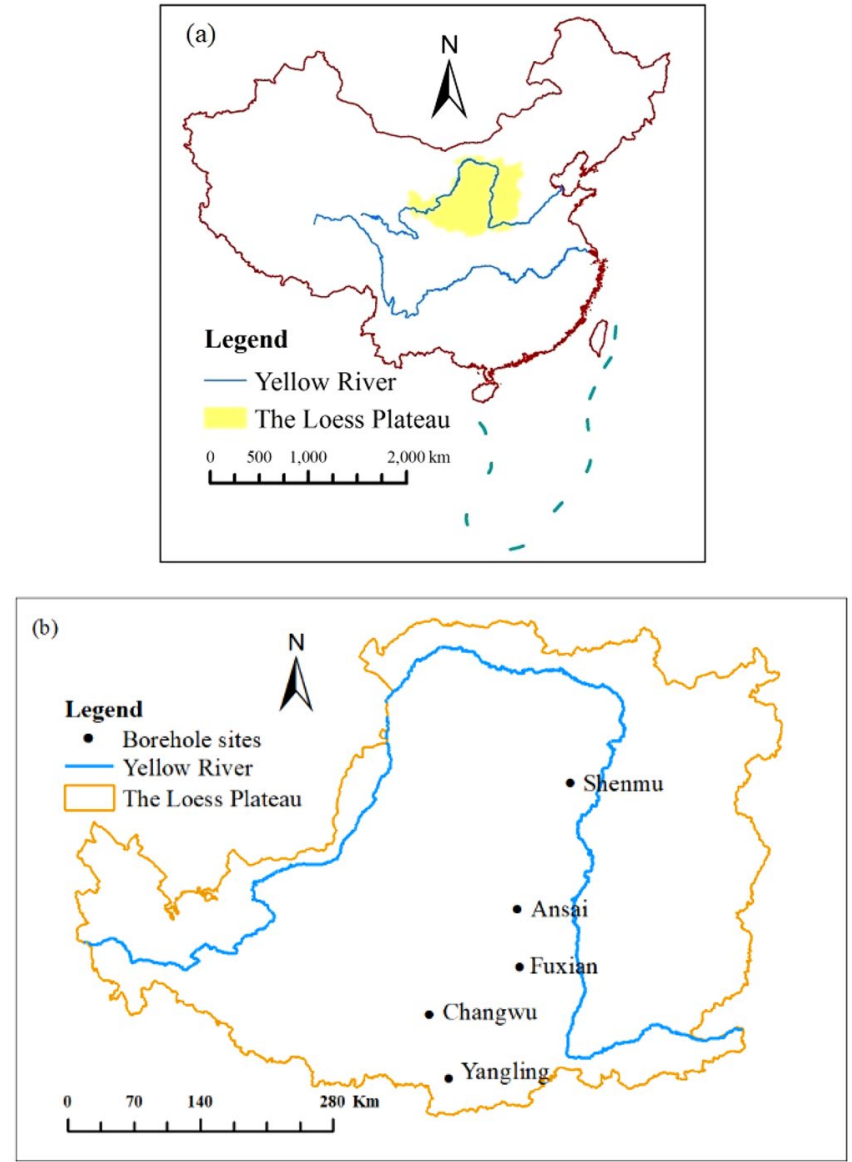

Figure 1. Locations of the Loess Plateau region in China (a) and the sampling sites (b); image data processed by ArcGIS 10.5 http://developers.arcgis.com.

\section{Materials and methods}

Study area. The study was conducted across the Loess Plateau $\left(33^{\circ} 43^{\prime}-41^{\circ} 16^{\prime} \mathrm{N}, 100^{\circ} 54^{\prime}-114^{\circ} 33^{\prime} \mathrm{E}\right)$ (Fig. 1a), which represents approximately $6.5 \%$ of the total area of China ${ }^{6}$. The study area is dominated by temperate, arid, and semiarid continental monsoon climates. The annual evaporation is $1400-2000 \mathrm{~mm}$, and the annual temperature ranges from $3.6^{\circ} \mathrm{C}$ in the northwest to $14.3^{\circ} \mathrm{C}$ in the southeast on the Loess Plateau ${ }^{7}$, while the annual precipitation ranges from 150 to $800 \mathrm{~mm}$, where $55-78 \%$ of the precipitation falls from June to September ${ }^{7}$. The annual solar radiation ranges from $5.0 \times 10^{9}$ to $6.7 \times 10^{9} \mathrm{~J} \mathrm{~m}^{-2}$. The vegetation zones are forest, forest-steppe, typical-steppe, desert-steppe, and steppe-desert zones ${ }^{8}$ from southeast to northwest.

Field sampling. According to the different climate zones and vegetation types, five classic sampling sites were selected (Fig. 1b) on the Loess Plateau, which were Yangling, Changwu, Fuxian, Ansai, and Shenmu from south to north. Drilling equipment (assembled by Xi'an Qinyan Drilling Co. Ltd, China) was used to collect soil samples from soil surface down to bedrock. At each sampling site, disturbed soil samples were collected to determine the SAP and SAK concentrations, $\mathrm{pH}$, soil particle composition, and soil organic matter contents. In addition, disturbed soil samples were collected from the middle of the soil column at 1-m intervals (i.e., $0.5 \mathrm{~m}, 1.5 \mathrm{~m}, 2.5 \mathrm{~m}, 3.5 \mathrm{~m}$, etc.). The drilling and sampling work was carried out from April 28 to June 28, 2016. The total numbers of disturbed soil samples collected from Yangling, Changwu, Fuxian, Ansai, and Shenmu were $103,205,181,161$, and 58, respectively, and the corresponding soil drilling depths were $103.5 \mathrm{~m}, 204.5 \mathrm{~m}$, $187.5 \mathrm{~m}, 161.6 \mathrm{~m}$, and $56.6 \mathrm{~m}$, respectively.

Laboratory analyses. Undisturbed soil samples were air-dried, separated, and passed through $0.25-\mathrm{mm}$ or 2-mm sieves. SAP and SAK were extracted with ammonium lactate solution and detected by spectrophotometry and flame photometry. Soil total nitrogen (STN) concentrations were determined by the Kjeldahl digestion procedure ${ }^{9}$. Soil total phosphorus (STP) concentrations were determined by molybdenum antimony blue colorimetry $^{10}$. The soil organic carbon (SOC) contents were analyzed by dichromate oxidation method ${ }^{11}$. The soil particle composition was determined by laser diffraction (Mastersizer 2000, Malvern Instruments, Malvern, $\mathrm{UK})^{12}$. According to the mixture of soil and water mass ratio of $1: 1$, the $\mathrm{pH}$ value was determined with a $\mathrm{pH}$ meter equipped with a calibrated combined glass electrode. The soil water content (SWC) was determined by the 
mass loss after drying to constant mass in an oven at $105^{\circ} \mathrm{C}^{13}$. The calcium carbonate content was determined by the acid-neutralization method $^{14}$.

Geostatistical analysis. The geostatistical analysis was chosen to determine the spatial structure of the spatially dependent soil properties ${ }^{15}$, where a semivariogram was employed to quantify the spatial patterns of the variables. The equation for the semivariogram is ${ }^{16}$ :

$$
\mathrm{R}(\mathrm{h})=\frac{1}{2 \mathrm{~N}(\mathrm{~h})} \sum_{\mathrm{i}=1}^{\mathrm{N}(\mathrm{h})}\left[\mathrm{Z}\left(\mathrm{x}_{\mathrm{i}}\right)-\mathrm{Z}\left(\mathrm{x}_{\mathrm{i}+\mathrm{h}}\right)\right]^{2},
$$

where for each site $\mathrm{i}, \mathrm{N}(\mathrm{h})$ is the number of pairs separated by $\mathrm{h}$, and $\mathrm{Z}\left(\mathrm{x}_{\mathrm{i}}\right)$ is the value at location $\mathrm{xi}$ and $\mathrm{Z}\left(\mathrm{x}_{\mathrm{i}+\mathrm{h}}\right)$ for $\mathrm{x}_{\mathrm{i}+\mathrm{h}}$. There are four semivariogram models (spherical, exponential, linear, and Gaussian), which can be employed to describe the semivariogram, and the best fitting model is selected according to the smallest residual sum of squares (RSS) and the largest coefficient of determination $\left(\mathrm{R}^{2}\right)$. The equation of each semivariogram model is ${ }^{16}$ :

Exponential model:

$$
\mathrm{R}(\mathrm{h})=\mathrm{C}_{0}+\mathrm{C}\left[\left(1-\exp \left(-\mathrm{h} / \mathrm{A}_{0}\right)\right]\right.
$$

Linear Model:

$$
\mathrm{R}(\mathrm{h})=\mathrm{C}_{0}+\left[\mathrm{h}\left(\mathrm{C} / \mathrm{A}_{0}\right)\right]
$$

Spherical Model:

$$
\begin{gathered}
\mathrm{R}(\mathrm{h})=\mathrm{C} 0+\mathrm{C}\left[1.5\left(\mathrm{~h} / \mathrm{A}_{0}\right)-0.5\left(\mathrm{~h} / \mathrm{A}_{0}\right)^{3}\right] \quad \mathrm{h} \leq \mathrm{A} 0 \\
\mathrm{R}(\mathrm{h})=\mathrm{C}_{0}+\mathrm{C} \quad \mathrm{h} \geq \mathrm{A} 0
\end{gathered}
$$

Gaussian Model:

$$
\mathrm{R}(\mathrm{h})=\mathrm{C}_{0}+\mathrm{C}\left[1-\exp \left(-\mathrm{h}^{2} / \mathrm{A}_{0}^{2}\right)\right]
$$

where $\mathrm{C}_{0}$ indicates the nugget value, which is the short-range structure that occurs at distances smaller than the sampling interval, microheterogeneity, and experimental error; $\mathrm{C}_{0}+\mathrm{C}$ is the sill indicating the random and structural variation, and; $\mathrm{A}_{0}$ is the range indicating the spatial correlation at different distances.

Statistical analysis. Descriptive statistical analyses (maximum, minimum, average, and coefficient of variation), Pearson's correlation analysis, and linear regression analysis was performed with SPSS 16.0 (IBM SPSS, Chicago, IL, USA). Geostatistical analysis was performed with GS + software (version 7.05).

\section{Results}

Vertical distributions of SAP and SAK. Figure 2 shows the vertical distribution of the SAP and SAK contents at all of the sampling sites. Trends in the SAP decreased among the different sampling sites, whereas the SAK concentration increased gradually with depth at all of the sampling sites.

Table 1 shows the descriptive statistics obtained for SAP and SAK at the different sampling sites. SAP ranged from 0.28 to $32.56 \mathrm{mg} \mathrm{kg}^{-1}$ at the sampling sites and SAK ranged from 44.51 to $229.31 \mathrm{mg} \mathrm{kg}^{-1}$. The CV values of SAP and SAK ranged from 0.26 to 0.67 and from 0.21 to 0.30 , respectively, and the SAP and SAK concentrations exhibited moderate variation at different sampling sites ${ }^{17}$. In addition, the mean SAP and SAK concentrations tended to decrease from south to north among the sampling sites.

Correlation analysis. Pearson's correlation coefficients were calculated to determine the strengths of the possible relationships between SAP and SAK with the other basic soil properties. Table 2 shows the Pearson's correlation coefficients obtained between SAP and SAK, and the selected soil properties.

The correlation analysis results obtained for SAP varied among the different sampling sites. For example, SAP had significant correlations with most of the selected variables (except for sand, STN, and SOC) at Changwu, but it was only significantly correlated with SWC at Ansai. Similar to SAP, the correlation analysis results varied for SAK at different sampling sites. At all of the sampling sites, SAK had significant positive correlations with the depth and clay content and significant negative correlations with the sand content.

Stepwise multiple linear regression analysis (SMLRA). Table 3 shows the results obtained by SMLRA between SAP, SAK, and the significantly correlated factors, which were conducted to determine the contributions of these independent variables to the variations in SAP or SAK. The adjusted $\mathrm{r}^{2}$ values for SAP ranged from 5.2 to $54.9 \%$, and those for SAK ranged from $44.6 \%$ to $64.3 \%$, thereby indicating that the selected soil properties explained more of the variation in SAK than SAP. For SAP, the adjusted $\mathrm{r}^{2}$ values obtained at Yangling, Changwu, Fuxian, Ansai, and Shenmu were 7.8\%, 32.6\%, 54.9\%, 16.3\%, and 5.2\%, respectively, and $49.5 \%, 49 \%, 44.6 \%, 59 \%$, and $64.3 \%$ for SAK. In addition, the independent variables that explained most of the variations in SAP at Yangling, Changwu, Fuxian, Ansai, and Shenmu were $\mathrm{CaCO}_{3}(7.8 \%)$, depth (30.4\%), depth (48.9\%), SWC (16.3\%), and STN (5.2\%), respectively, and depth (28.4), clay (33.1\%), STP (25.4\%), clay (37.3\%), and depth (29.8\%) for SAK. 

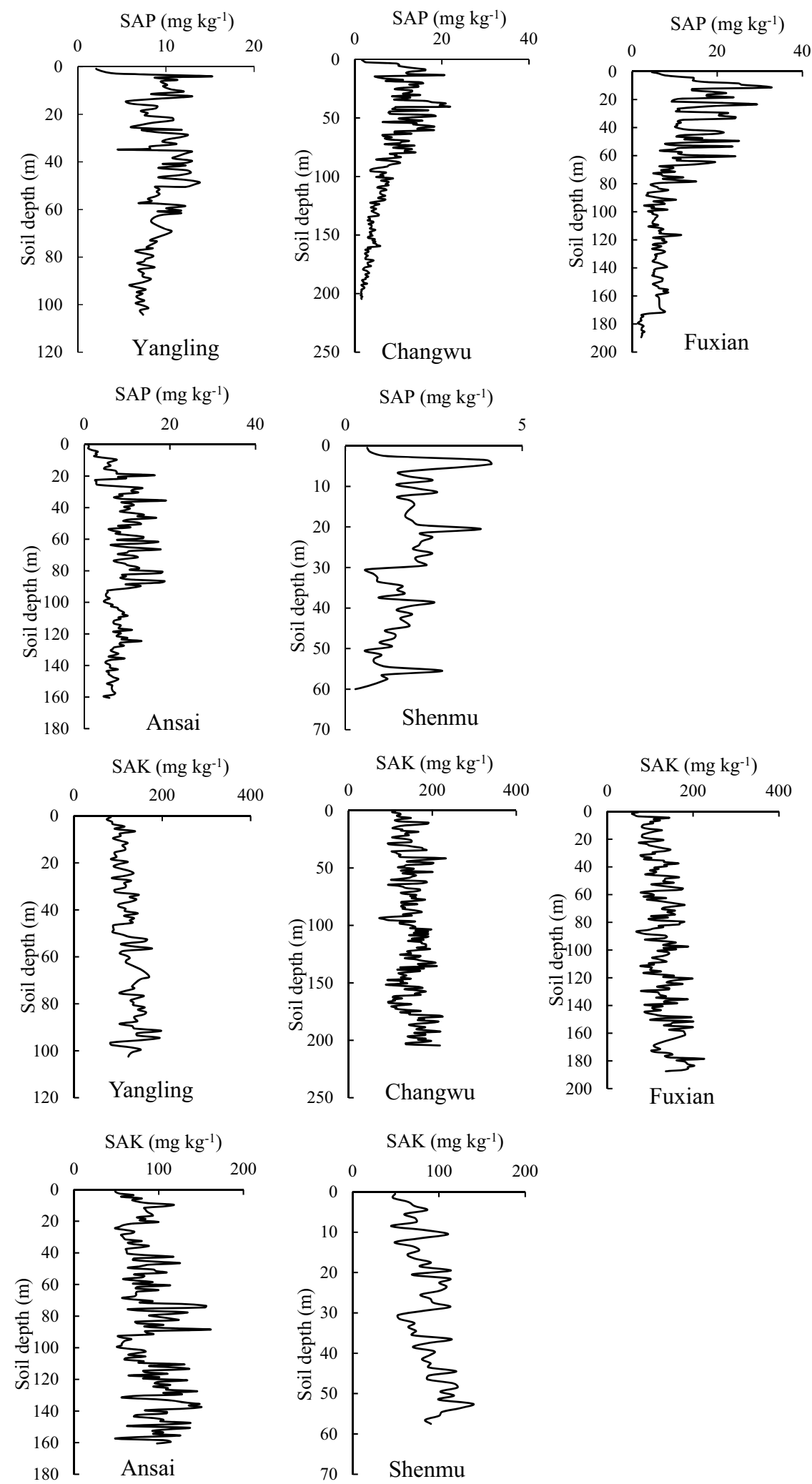

Figure 2. Vertical distributions of SAP and SAK concentrations at different sampling sites; the data extracted from GS + and mapped by Excel https://www.microsoft.com/zh-cn/microsoft-365/excel. 


\begin{tabular}{|l|l|l|l|l|r|l|}
\hline SS & SCP & No & Min & Max & Mean & CV \\
\hline \multirow{3}{*}{ Yangling } & SAP & 103 & 2.10 & 15.19 & 9.03 & 0.26 \\
\cline { 2 - 7 } & SAK & 103 & 58.78 & 197.80 & 122.34 & 0.21 \\
\hline \multirow{3}{*}{ Changwu } & SAP & 205 & 2.28 & 21.69 & 10.60 & 0.38 \\
\cline { 2 - 7 } Fuxian & SAK & 205 & 74.07 & 229.31 & 149.01 & 0.21 \\
\hline \multirow{3}{*}{ Ansai } & SAP & 181 & 1.39 & 32.56 & 9.42 & 0.67 \\
\cline { 2 - 7 } & SAK & 181 & 57.81 & 225.83 & 127.62 & 0.26 \\
\hline \multirow{2}{*}{ Shenmu } & SAP & 161 & 0.94 & 19.10 & 8.39 & 0.43 \\
\cline { 2 - 7 } & SAK & 161 & 48.51 & 161.29 & 88.15 & 0.30 \\
\cline { 2 - 7 } & SAP & 58 & 0.28 & 4.45 & 3.64 & 0.25 \\
\cline { 2 - 7 } & SAK & 58 & 44.51 & 139.17 & 86.16 & 0.25 \\
\hline
\end{tabular}

Table 1. Descriptive statistics for the soil available phosphorus (SAP) and soil available potassium (SAK) concentrations at different sampling sites. SS sampling site, SCP soil chemical property, No. Number, Min minimum, Max maximum, $C V$ coefficient of variation, $S A P$ soil available phosphorus, $S A K$ soil available potassium.

\begin{tabular}{|c|c|c|c|c|c|c|c|c|c|c|}
\hline \multirow[b]{2}{*}{ SCP } & \multicolumn{2}{|c|}{ Yangling } & \multicolumn{2}{|c|}{ Changwu } & \multicolumn{2}{|l|}{ Fuxian } & \multicolumn{2}{|l|}{ Ansai } & \multicolumn{2}{|c|}{ Shenmu } \\
\hline & SAP & SAK & SAP & SAK & SAP & SAK & SAP & SAK & SAP & SAK \\
\hline Depth & $-0.25^{*}$ & $0.54^{* *}$ & $-0.55^{* *}$ & $0.24^{* \star}$ & $-0.70^{* *}$ & $0.46^{* *}$ & -0.05 & $0.39^{* *}$ & 0.12 & $0.56^{* *}$ \\
\hline SAK & -0.16 & 1 & $-0.27^{* *}$ & 1 & $-0.39^{* *}$ & 1 & 0.09 & 1 & 0.24 & 1 \\
\hline SAP & 1 & -0.16 & 1 & $-0.27^{* *}$ & 1 & $-0.39^{* \star}$ & 1 & 0.09 & 1 & 0.24 \\
\hline SWC & 0.16 & -0.13 & $0.48^{* *}$ & $-0.32^{\star \star}$ & $-0.27^{* *}$ & $0.18^{\star}$ & $0.41^{* *}$ & $0.26^{* *}$ & 0.22 & $0.54^{* *}$ \\
\hline Sand & 0.004 & $-0.30^{* *}$ & -0.02 & $-0.49^{* *}$ & $0.15^{\star}$ & $-0.42^{* *}$ & -0.14 & $-0.64^{* *}$ & -0.25 & $-0.48^{\star \star}$ \\
\hline Silt & -0.06 & $-0.26^{*}$ & $0.38^{* *}$ & $-0.31^{\star *}$ & 0.05 & $-0.15^{*}$ & 0.12 & $0.45^{\star \star}$ & 0.21 & $0.43^{* *}$ \\
\hline Clay & 0.04 & $0.33^{* *}$ & $-0.27^{* *}$ & $0.58^{\star \star}$ & $-0.17^{*}$ & $0.49^{* \star}$ & 0.1 & $0.61^{* *}$ & 0.21 & $0.36^{* *}$ \\
\hline STP & $0.29^{* *}$ & $-0.25^{*}$ & $0.14^{*}$ & $-0.35^{* *}$ & $0.29^{* *}$ & $-0.51^{* *}$ & -0 & $-0.23^{* *}$ & -0.03 & -0.18 \\
\hline STN & -0.18 & -0.08 & 0.1 & $0.16^{\star}$ & $0.16^{\star}$ & 0.01 & 0.12 & $0.45^{\star \star}$ & $0.26^{*}$ & $0.50^{* *}$ \\
\hline SOC & -0.03 & $-0.36^{* *}$ & 0.11 & -0.006 & $0.21^{* *}$ & $-0.19^{* *}$ & -0.01 & -0.007 & 0.04 & -0.18 \\
\hline $\mathrm{pH}$ & -0.12 & 0.16 & $0.22^{\star \star}$ & 0.03 & $-0.35^{\star \star}$ & $0.29^{* *}$ & -0.14 & 0.15 & -0.22 & $-0.58^{* x}$ \\
\hline $\mathrm{CaCO}_{3}$ & $0.30^{* *}$ & $-0.49^{* *}$ & $-0.23^{* *}$ & $-0.24^{* *}$ & -0.06 & -0.14 & 0.05 & $-0.61^{* *}$ & 0.15 & -0.12 \\
\hline
\end{tabular}

Table 2. Pearson's correlation coefficients between the soil available phosphorus (SAP), soil available potassium (SAK), and selected soil properties. SCP soil chemical properties, SWC soil water content, STN soil total nitrogen, $S T P$ soil total phosphorus, $S O C$ soil organic carbon, $S A P$ soil available phosphorus, $S A K$ soil available potassium. ${ }^{\star}$ Correlation is significant at the 0.05 level. ${ }^{*}$ Correlation is significant at the 0.01 level.

Spatial structure of the SAP and SAK. Geostatistical analysis was conducted to analyze the spatial structure of variations in SAP and SAK. Table 4 shows the best geostatistical models that fit each variogram of SAP and SAK for the sampling sites, which has the lowest RSS values and highest $\mathrm{R}^{2}$ values. Figure 3 shows the semivariogram for the distribution of the SAP and SAK, where the solid line represents the best-fit model. Clearly, most variograms of SAP and SAK were fitted with an exponential model for all sampling sites (Table 4). In addition, Table 4 shows the spatial structure parameters, which are derived from the best-fitted models. Nugget values $\left(C_{0}\right)$ indicate undetectable experimental error and field variation within the minimum sampling space. Nugget values of SAP of Yangling, Changwu, Fuxian, Ansai and Shenmu were 3.41, 6.07, 14, 6.1 and 1.35, respectively, while values were $0.000001,0.0001,0.000001,0.0003$ and 0.0002 , respectively, for SAK (Table 4). Clearly, the nugget values of SAP and SAK were low, especially for SAK. This result indicated that there were a small undetectable experimental error and field variation within the minimum sampling space. The Sill values $\left(\mathrm{C}_{0}+\mathrm{C}\right)$ of SAP and SAK ranged from 5.71 to 49 and from 0.000001 to 0.001 , respectively, which indicated the total spatial variation.

The value of $\mathrm{C}_{0} /\left(\mathrm{C}+\mathrm{C}_{0}\right)$ shows the degree of spatial dependence. For $\mathrm{SAP}$, the value of $\mathrm{C}_{0} /\left(\mathrm{C}+\mathrm{C}_{0}\right)$ ranged from 0.29 to 0.5 at the Yangling, Changwu, Fuxian, Ansai sampling sites and showed a moderate spatial dependence (except for Shenmu) according to the criterion of Cambardella et al. ${ }^{18}$. For SAK, Ansai and Shenmu showed moderate spatial dependence, while the rest showed strong spatial dependence. The spatial dependence of SAP and SAK was influenced by many factors, including intrinsic factors (soil texture, mineralogy, etc.) and extrinsic factors (soil fertilization, human activities, etc.), leading to different spatial dependence of SAP and SAK. The range was used to assess the correlated distance of soil properties, and the ranges of SAP and SAK ranged from $38.50 \mathrm{~m}$ to $473.10 \mathrm{~m}$ and from $1.89 \mathrm{~m}$ to $18.06 \mathrm{~m}$, respectively. This result indicated that our sampling density was adequate for detecting the spatial autocorrelation distance of SAP and SAK. 


\begin{tabular}{|c|c|c|c|c|c|c|c|}
\hline SS & DV & IV & Coefficient & SE & $\mathbf{P}$ & EV & Adjusted $\mathbf{r}^{2}$ \\
\hline \multirow{6}{*}{ Yangling } & \multirow{2}{*}{ SAP } & Constant & 8.098 & 0.408 & 0.000 & & 0.078 \\
\hline & & $\mathrm{CaCO}_{3}$ & 0.015 & 0.005 & 0.003 & 0.078 & \\
\hline & \multirow{4}{*}{ SAK } & Constant & 66.549 & 14.753 & 0.000 & & \\
\hline & & Depth & 0.399 & 0.063 & 0.000 & 0.284 & 0.495 \\
\hline & & $\mathrm{CaCO}_{3}$ & -0.172 & 0.040 & 0.000 & 0.143 & \\
\hline & & Clay & 1.655 & 0.452 & 0.000 & 0.067 & \\
\hline \multirow{9}{*}{ Changwu } & \multirow{3}{*}{ SAP } & Constant & 19.470 & 1.072 & 0.000 & & 0.326 \\
\hline & & Depth & -0.051 & 0.005 & 0.000 & 0.304 & \\
\hline & & SWC & -2.402 & 0.467 & 0.000 & 0.022 & \\
\hline & \multirow{6}{*}{ SAK } & Constant & 178.258 & 24.913 & 0.000 & & 0.490 \\
\hline & & Clay & 2.187 & 0.438 & 0.000 & 0.331 & \\
\hline & & $\mathrm{CaCO}_{3}$ & -0.267 & 0.039 & 0.000 & 0.101 & \\
\hline & & SAP & -1.372 & 0.455 & 0.003 & 0.033 & \\
\hline & & Sand & -1.424 & 0.557 & 0.011 & 0.011 & \\
\hline & & SWC & -1.708 & 0.670 & 0.012 & 0.014 & \\
\hline \multirow{10}{*}{ Fuxian } & \multirow{4}{*}{ SAP } & Constant & -53.126 & 23.550 & 0.025 & & 0.549 \\
\hline & & Depth & -0.114 & 0.009 & 0.000 & 0.489 & \\
\hline & & STN & -23.894 & 6.265 & 0.000 & 0.035 & \\
\hline & & $\mathrm{pH}$ & 9.063 & 2.781 & 0.001 & 0.025 & \\
\hline & \multirow{6}{*}{ SAK } & Constant & 125.460 & 22.385 & 0.000 & & 0.446 \\
\hline & & STP & -107.268 & 19.443 & 0.000 & 0.254 & \\
\hline & & Clay & 0.947 & 0.544 & 0.083 & 0.097 & \\
\hline & & SWC & 1.753 & 0.590 & 0.003 & 0.058 & \\
\hline & & Depth & 0.133 & 0.042 & 0.002 & 0.024 & \\
\hline & & Sand & -1.259 & 0.565 & 0.027 & 0.013 & \\
\hline \multirow{7}{*}{ Ansai } & \multirow{2}{*}{ SAP } & Constant & 2.976 & 0.988 & 0.003 & & 0.163 \\
\hline & & SWC & 0.314 & 0.055 & 0.000 & 0.163 & \\
\hline & \multirow{5}{*}{ SAK } & Constant & 50.927 & 8.696 & 0.000 & & 0.590 \\
\hline & & Clay & 1.616 & 0.364 & 0.000 & 0.373 & \\
\hline & & $\mathrm{CaCO}_{3}$ & -0.259 & 0.039 & 0.000 & 0.179 & \\
\hline & & STN & 123.572 & 31.939 & 0.000 & 0.018 & \\
\hline & & Depth & 0.108 & 0.037 & 0.004 & 0.020 & \\
\hline \multirow{5}{*}{ Shenmu } & \multirow{2}{*}{ SAP } & Constant & 4.107 & 0.808 & 0.000 & & 0.052 \\
\hline & & STN & 13.051 & 6.433 & 0.047 & 0.052 & \\
\hline & \multirow{3}{*}{ SAK } & Constant & 3.531 & 8.990 & 0.696 & & 0.643 \\
\hline & & Depth & 0.836 & 0.104 & 0.000 & 0.298 & \\
\hline & & STN & 476.166 & 64.153 & 0.000 & 0.345 & \\
\hline
\end{tabular}

Table 3. Results obtained by multiple stepwise regression analyses between SAP, SAK, and the significantly correlated factors. $S S$ sampling sites, $D V$ dependent variable, $I V$ independent variable, $S E$ standard error, $E V$ explained variation, $P$ significance level.

\begin{tabular}{|l|l|l|l|l|l|l|l|l|}
\hline SS & SP & Model & $\mathbf{C}_{\mathbf{0}}$ & $\mathbf{C}_{\mathbf{0}}+\mathbf{C}$ & $\mathbf{C}_{\mathbf{0}} / \mathbf{C}_{\mathbf{0}}+\mathbf{C}$ & $\mathbf{A}_{\mathbf{0}}$ & $\mathbf{R}$ & $\mathbf{R}^{2}$ \\
\hline \multirow{2}{*}{ Yangling } & SAP & Gaussian & 3.41 & 10.3 & 0.33 & 71.01 & 0.8 & 0.98 \\
\cline { 2 - 9 } & SAK & Spherical & 0.000001 & 0.0005 & 0.002 & 1.89 & $4.413 \mathrm{E}-08$ & 0.29 \\
\hline \multirow{3}{*}{ Changwu } & SAP & Spherical & 6.07 & 12.15 & 0.5 & 38.5 & 7.31 & 0.87 \\
\cline { 2 - 9 } Fuxian & SAK & Exponential & 0.0001 & 0.001 & 0.11 & 5.97 & $6.233 \mathrm{E}-08$ & 0.78 \\
\hline \multirow{2}{*}{ Ansai } & SAP & Exponential & 14 & 49 & 0.29 & 322.5 & 64.8 & 0.78 \\
\cline { 2 - 9 } & SAK & Exponential & 0.000001 & 0.0008 & 0.0011 & 3.78 & $8.11 \mathrm{E}-08$ & 0.63 \\
\hline \multirow{2}{*}{ Shenmu } & SAP & Exponential & 6.1 & 14.84 & 0.41 & 59.7 & 4.26 & 0.94 \\
\cline { 2 - 9 } & SAK & Exponential & 0.0003 & 0.0007 & 0.48 & 18.06 & $3.816 \mathrm{E}-08$ & 0.76 \\
\cline { 2 - 8 }$y$ & SAP & Exponential & 1.35 & 5.71 & 0.24 & 473.1 & 2.48 & 0.44 \\
\hline
\end{tabular}

Table 4. Spatial structure parameters of soil available phosphorus (SAP) and soil available potassium (SAK) for the sampling sites. $S S$ sampling sites, $S P$ structure parameters, $C_{0}$ nugget, $C_{0}+C$ sill, $C_{0} /\left(C_{0}+C\right)$ anisotropy ratio, $A_{0}$ range, $R S S$ residual sum of squares, $R^{2}$ coefficient of determination. 

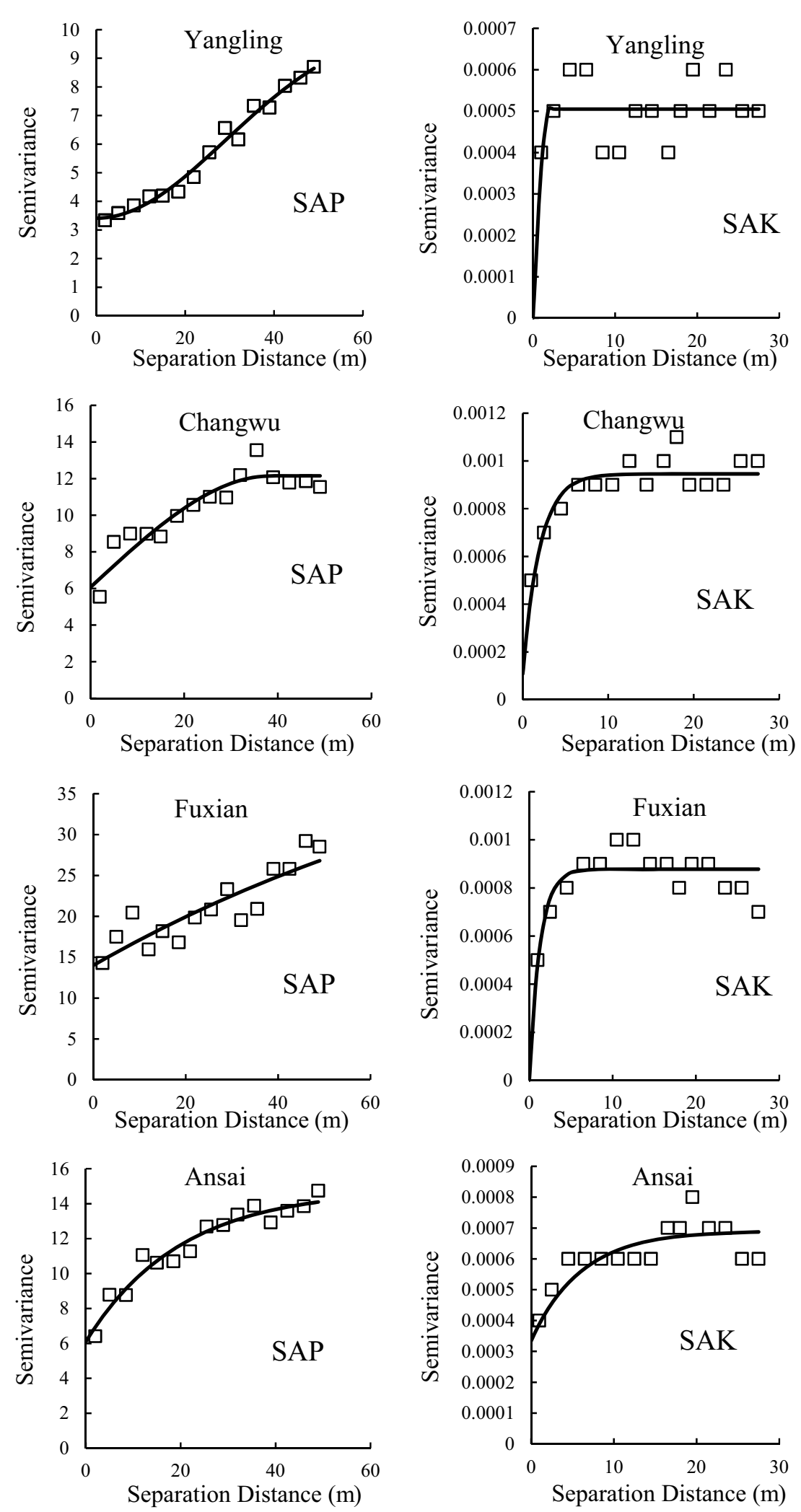

Figure 3. Semivariograms of soil available phosphorus (SAP) and soil available potassium for the sampling sites; the data extracted from GS + and mapped by Excel https://www.microsoft.com/zh-cn/microsoft-365/excel. 

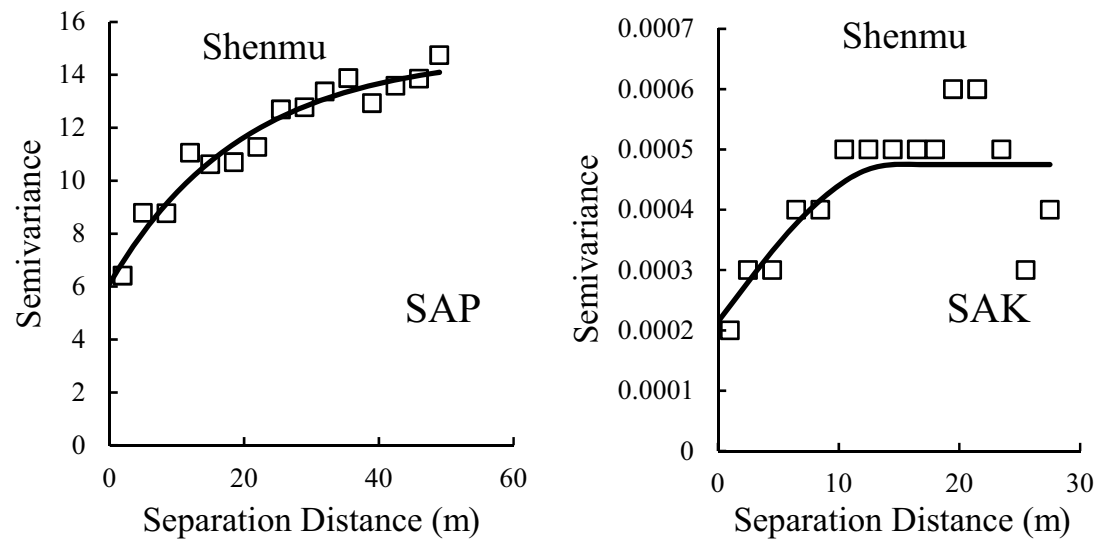

Figure 3. (continued)

\section{Discussion}

Effect on the formation of SAP and SAK on the Loess Plateau. The content of SAP all showed a downward trend at the five sampling sites. SAP is influenced by many factors, including the soil parent material, geographical position, and soil physical and chemical properties ${ }^{19}$. Element $\mathrm{P}$ of the deep profile mainly comes from the release of apatite on the Loess Plateau. The bedrock is covered by three loess layers, including Wucheng Loess, Lishi Loess, and Malan Loess on the Loess Plateau. Liu et al. ${ }^{20}$ found that the mean P content of Wucheng loess and the lower part of Lishi loess were lower than that of the upper part of Lishi loess and Malan loess, leading to a decreasing trend in element P. Thus, SAP showed a decreasing trend. We also found that SAK tended to increase at all of the sampling sites along with the profile (Fig. 2). Additionally, SAK was also influenced by many factors, but clay was the key factor that affected the variations because clay has a high adsorption capacity for $\mathrm{SAK}^{21}$. Furthermore, the clay content increased with the depth at all of the sampling sites (data not shown). Liu et al. ${ }^{13}$ also found that clay content showed an increasing trend by measuring the soil particle compositions for the typical Luochuan loess profile, thereby leading to an increasing trend in SAK.

The mean SAP and SAK contents tended to decrease from south to north, that is, from Yangling to Changwu, Fuxian, Ansai, and Shenmu. Two reasons may explain the changes in the SAP concentration, as follows: (1) The temperature and precipitation increased from north to south among the sampling sites, and thus, $\mathrm{P}$ was more readily weathered and released from rocks ${ }^{22}$, thereby leading to an increase in the soil total $\mathrm{P}$ from north to south ${ }^{23}$. In addition, there was a positive correlation between the STP and SAP contents ${ }^{13}$. Therefore, the SAP contents tended to decrease from south to north among the sampling sites. (2) In addition to plants and fertilization, the soil texture is an important factor that influences the variations in the SAP contents in the deep profile. Soil with a higher adsorption capacity has a greater clay content ${ }^{19}$ and $^{24}$ showed that clay has a higher SAP content compared to sand. We found that the clay content tended to decrease from south to north among the sampling sites, and thus, SAP content was higher in the south. SAK is also influenced by many factors, such as cultivation, soil texture, $\mathrm{pH}$, and temperature. Therefore, given the depths of the sampling sites, the soil texture is an important factor that influences the SAK concentration because the clay content has important effects on the adsorption of $\mathrm{SAK}^{21}$. We found that the mean clay content tended to decrease among the sampling sites from south to north, and thus the mean SAK content decreased from south to north.

Relationship between soil properties and SAP and SAK. The analysis was conducted based on the Pearson's correlation coefficients to determine the strengths of the possible relationships between SAP and SAK, and their relationships with other soil properties. The correlation analysis results obtained for SAP varied among the different sampling sites. In addition, SMLRA showed the adjusted $\mathrm{r}^{2}$ values were low for SAP (except at Fuxian), thereby indicating that a complex array of factors influenced the SAP contents ${ }^{13,19}$. The results were also different for SAK, but the SAK contents determined at all of the sampling sites had significant positive correlations with the depth and clay content, while there was a significant negative correlation with the sand content. In addition, SMLRA of SAK showed the adjusted $\mathrm{r}^{2}$ values were high, and then depth and clay content were important variables to explain most of the variation in the SAK contents. Thus, clay was an important variable for SAK. In addition, depth is also an important variable for SAK variation because depth showed an increasing trend, as well as also an increasing trend for SAK, leading to a significant relationship between depth and SAK.

\section{Conclusions}

In this study, we investigated five typical sampling sites on the Loess Plateau, China, and determined the spatial variations in the SAP and SAK from the top of the soil profile down to the bedrock. SAP showed an increasing trend along with the profile at the five sites and a decreasing trend for SAK. The mean SAP and SAK contents tended to decrease from south to north among the sampling sites. Clay and depth were important variables for explaining the variations in SAK. The mechanism responsible for the variations in the SAP content is complex, and many variables need to be considered to understand these changes. The exponential model could fit most variograms of SAP and SAK for all sampling sites. Due to the influence of many factors, such as human activities, 
soil texture and other factors, SAP and SAK at different sampling sites showed different spatial correlations. Our study is a basic study on the content changes of soil SAP and SAK in the deep profile of Loess Plateau, which can provide new ideas for the investigation of the biogeochemical cycle.

Received: 27 August 2020; Accepted: 18 January 2021

Published online: 04 February 2021

\section{References}

1. Li, L., Yao, Y. \& Qin, F. Spatial variability of soil total nitrogen, available phosphorus and available potassium in Huanghuadianzi watershed. Chin. J. Ecol. 34, 373-379 (2015).

2. Bogunovic, I., Pereira, P. \& Brevik, E. C. Spatial distribution of soil chemical properties in an organic farm in Croatia. Sci. Total Environ. 584, 535-545 (2017).

3. Chen, Y., Luo, Y., Li, Y., Han, J. \& Zhao, X. Characteristics of soil available P and K of farmland in Lanzhou area. Bull. Soil Water Conserv. 34, 46-52 (2014).

4. Zhu, Y., Jia, X. \& Shao, M. Loess thickness variations across the Loess Plateau of China. Surv. Geophys. 4, 715-725 (2018).

5. Tan, H., Liu, Z., Rao, W., Jin, B. \& Zhang, Y. Understanding recharge in soil-groundwater systems in high loess hills on the Loess Plateau using isotopic data. CATENA 156, 18-29 (2017).

6. Liu, Z. P., Shao, M. A. \& Wang, Y. Q. Spatial patterns of soil total nitrogen and soil total phosphorus across the entire Loess Plateau region of China. Geoderma 197-198, 67-78 (2013).

7. Shi, H. \& Shao, M. Soil and water loss from the Loess Plateau in China. J. Arid Environ. 45, 9-20 (2000).

8. Wang, Y., Shao, M. A. \& Liu, Z. Vertical distribution and influencing factors of soil water content within $21 \mathrm{~m}$ profile on the Chinese Loess Plateau. Geoderma 193-194, 300-310 (2013).

9. Bremner, J. M. \& Tabatabai, M. A. Use of an ammonia electrode for determination of ammonium in Kjeldahl analysis of soils. Commun. Soil Sci. Plant Anal. 3, 159-165 (1972).

10. Murphy, J. \& Riley, J. P. A modified single solution method for the determination of phosphate in natural waters. Anal. Chim. Acta 27, 31-36 (1962).

11. Nelson, D. W. et al. Total carbon, organic carbon, and organic matter. Methods Soil Anal. 1, 961-1010 (1982).

12. Liu, Y. P., Tong, J. \& Li, X. N. Analysing the silt particles with the Malvern Mastersizer 2000 (Water Conservancy Science \& Technology \& Economy, New York, 2005).

13. Wang, Y., Chen, X. \& Shi, Y. Phosphorus availability in cropland soils of China and related affecting factors. Chin. J. Appl. Ecol. 24, 260-268 (2013).

14. Allison, L. E. \& Moodie, C. D. Carbonate. In Methods of soil analysis, part 2: Chemical and microbiological properties (ed. Black, C. A.) 1379-1396 (American Society of Agronomy, Inc., Madison, 1965).

15. Western, A. W. et al. Spatial correlation of soil moisture in small catchments and its relation to dominant spatial hydrological processes. J. Hydrol. 286, 113-134 (2004).

16. Faisal, F., Novianti, P. \& Rizal, J. The application of spatial analysis and time series in modeling the frequency of earthquake events in bengkulu province. Aceh Int. J. Sci. Technol. 7, 103-114 (2018).

17. Nielsen, D.R. \& Bouma, J., 1985. Soil spatial variability: Proceedings of a workshop of the ISSS and the SSSA, Las Vegas, USA, 30 November-1 December, 1984. Pudoc.

18. Cambardella, C. A. et al. Field-scale variability of soil properties in central iowa soils. Soil. Soc. Am. J. 58, 1501-1511 (1994).

19. Qin, S., Liu, J. \& Wang, G. Mechanism of phosphorus availability changing in soil. Chin. J. Soil Sci. 37, 1012-1016 (2006).

20. Liu, D. S. Loess and Environment (Science Press, Beijing, 1985).

21. Wang, Z., Lu, J., Zhang, W. \& Li, X. Influential factors on soil available potassium evaluation in agriculture. Soils 44, 898-904 (2012).

22. Lin, J. S. et al. Storage and spatial variation of phosphorus in paddy soils of China. Pedosphere 19, 790-798 (2009).

23. Qiao, J., Zhu, Y., Jia, X., Huang, L. \& Shao, M. Vertical distribution of soil total nitrogen and soil total phosphorus in the critical zone on the Loess Plateau, China. CATENA 160, 310-316 (2018).

24. Gu, Y., Jiang, B. \& Lu, R. Effect of weathering on the transformation and availability of phosphorus in different fractions of particle size of main soils of China. Acta Pedol. Sin. 21, 134-143 (1984).

\section{Acknowledgements}

This study was supported by the strategy Priority Research Program of Chinese Academy of Sciences (XDB40000000), the National Natural Science Foundation of China for a major international cooperation programme between China and England (415711300781), the National Natural Science Foundation of China (41371242 and 41530854), and the Key Deployment Project of the Chinese Academy (KFZD-SW-306). The authors thank the editor and reviewers for their valuable comments and suggestions.

\section{Author contributions}

H.T. and J.Q. wrote the main manuscript text and Y.Z. revised some contents. All authors reviewed the manuscript..

\section{Competing interests}

The authors declare no competing interests.

\section{Additional information}

Correspondence and requests for materials should be addressed to Y.Z.

Reprints and permissions information is available at www.nature.com/reprints.

Publisher's note Springer Nature remains neutral with regard to jurisdictional claims in published maps and institutional affiliations. 
(c) (i) Open Access This article is licensed under a Creative Commons Attribution 4.0 International cc) License, which permits use, sharing, adaptation, distribution and reproduction in any medium or format, as long as you give appropriate credit to the original author(s) and the source, provide a link to the Creative Commons licence, and indicate if changes were made. The images or other third party material in this article are included in the article's Creative Commons licence, unless indicated otherwise in a credit line to the material. If material is not included in the article's Creative Commons licence and your intended use is not permitted by statutory regulation or exceeds the permitted use, you will need to obtain permission directly from the copyright holder. To view a copy of this licence, visit http://creativecommons.org/licenses/by/4.0/.

(C) The Author(s) 2021 